\title{
ARQUITECTURA Y URBANISMO DE COLONIA PATRICIA EN ÉPOCA ADRIANEA: NUEVAS APORTACIONES
}

\section{ARCHITECTURE AND URBANISM OF COLONIA PATRICIA IN HADRIAN'S TIMES: NEW CONTRIBUTIONS}

\author{
MANUEL D. RUIZ-BUENO \\ Dpto. de Historia del Arte, Arqueología y Música. Fac. de Filosofía y Letras, \\ Plaza del Cardenal Salazar no 3, 14071, Córdoba, España. \\ Correo-e: mdruizbueno@gmail.com D https://orcid.org/0000-0001-9265-6979 \\ ResearcherID: https://publons.com/researcher/K-5250-2017 \\ ANA PORTILLO GÓMEZ \\ Dpto. de Historia del Arte, Arqueología y Música. Fac. de Filosofía y Letras, \\ Plaza del Cardenal Salazar no 3, 14071, Córdoba, España. \\ Correo-e: aportillogomez@gmail.com D https://orcid.org/0000-0003-0051-846X \\ ResearcherID: https://publons.com/researcher/AAW-2323-2020
}

\begin{abstract}
Resumen: La llegada al poder de Adriano no solo influyó en Italica, sino que también parece haber repercutido en Córdoba, caput provinciae de Baetica. El objetivo de la presente contribución es tratar de reconstruir la imagen urbana de $\mathrm{Co}$ lonia Patricia en época adrianea, prestando especial atención a la arquitectura pública, pero sin olvidar la infraestructura defensiva, viaria e hidráulica, así como la arquitectura doméstica, productiva y funeraria. A la hora de alcanzar dicha meta hemos recopilado y analizado diversos testimonios arqueológicos, arquitectónicos, escultóricos y epigráficos. Aun cuando en muchos casos la documentación sugiera una datación del siglo II d.C., o más concretamente de la primera mitad de dicha centuria, en ocasiones sí hemos podido identificar determinados elementos bien fechados en época adrianea Palabras claves: Córdoba, Adriano, inmuebles públicos, primera mitad del siglo II d.C.
\end{abstract}

\begin{abstract}
Hadrian's government impacted not only in Italica, but also in Corduba, caput provinciae of Baetica. The aim of this contribution is to reconstruct the urban image of Colonia Patricia during Hadrian's times, highlighting the public architecture, without forgetting the defensive, road, and hydraulic infrastructures, as well as the residential, industrial, and funerary architectures. In order to achieve this objective, we have gathered and studied a wide range of archaeological, architectural, sculptural and epigraphic testimonies. Although in many cases the available documentation suggests a dating within the second century $\mathrm{AD}$, it has been possible to identify certain elements dated in Hadrian's times.
\end{abstract}

Keywords: Córdoba, Hadrian, public buildings, first half of the second century AD. 


\section{INTRODUCCIÓN}

«No deja de ser hasta cierto punto sorprendente que nada concreto sepamos de la capital provincial (bética) durante el gobierno de los dos emperadores hispanos, Trajano y Adriano» (Rodríguez 1988: 287).

Hace 30 años, Rodríguez Neila puso de relieve la nula información proporcionada por las fuentes literarias clásicas acerca de la historia y fisonomía de Colonia Patricia en las primeras décadas del siglo II d.C. Por fortuna, la revisión de antiguos hallazgos y la multiplicación de intervenciones arqueológicas han revertido sensiblemente la situación, de modo que es posible ofrecer una imagen más aproximada de la urbe en estos momentos. De hecho, incluso contamos con algunos testimonios arqueológicos que han podido ser datados con bastante precisión hacia época adrianea.

Córdoba, como otras tantas ciudades de la península ibérica, cuenta con una prolongada historia. De cara al período aquí analizado, tan solo hay que recordar que hacia los años 169-168 a.C. o quizás 152-151 a.C. se fundó la colonia romana de Corduba, capital de facto de la Hispania Ulterior desde mediados del siglo II a.C. Se trataba de un núcleo de una gran extensión (47 hectáreas in urbe), situado unos $750 \mathrm{~m}$ al noreste del primitivo oppidum turdetano existente (que paulatinamente fue despoblándose), y a más de $420 \mathrm{~m}$ de distancia del río Baetis. Décadas más tarde, tras la destrucción de la ciudad por las tropas cesarianas durante el conflicto civil que enfrentó a Julio César contra los hijos de Pompeyo (45 a.C.), Córdoba entró en una fase de recuperación y crecimiento que supuso, entre otros cambios, la ampliación de la urbe hacia el río (alcanzando una superficie intramuros que rondaba las 78 hectáreas); un cambio en su estatus jurídico y la sustitución del antiguo topónimo turdetano de Corduba por el de Colonia Patricia. Finalmente, tras el tercer viaje de Augusto a Hispania (15-13 a.C.), la ciudad fue nombrada capital de la recién creada provincia Baetica, manteniendo dicho estatus a lo largo de todo el Alto Imperio (Vaquerizo y Ruiz 2014: 16-17). Paralelamente, la urbe se dotó de los equipamientos inherentes a una capital provincial, de modo que la «imagen urbana de Colonia Patricia estaba prácticamente configurada al producirse el advenimiento de la dinastía flavia» (Murillo 2010: 92).

Hacia la primera mitad del siglo II d.C., Córdoba no parece haberse visto inmersa en grandes proyectos urbanísticos como los que tuvieron lugar en ciudades hispanas como Bracara Augusta (Martins y Fontes 2010: 111) y especialmente Italica (Caballos et al. 2006:
31-32 y 61 ss.), pero no por ello la fisonomía de la urbe permaneció inalterada, tal y como pondremos de relieve a continuación.

\section{INFRAESTRUCTURA DEFENSIVA, VIARIA E HIDRÁULICA}

A inicios de época antonina, Colonia Patricia contaba con un recinto amurallado con un perímetro cercano a los $3700 \mathrm{~m}$, que consistía grosso modo en dos paramentos paralelos (muro exterior e interior) separados entre sí por un terraplén (agger) que funcionó como camino de ronda. El recinto vigente por entonces no fue sino el resultado de una serie de obras y reformas que se iniciaron hacia los comedios del siglo II a.C., cuando la ciudad republicana quedó rodeada por una muralla con un grosor medio que rondaba los $9 \mathrm{~m}$. Tras la ampliación de la primitiva urbe hacia el río, el nuevo sector urbanizado quedó circunscrito por una muralla con un espesor medio menor (2-3 m), que se levantó entre mediados del siglo I a.C. y mediados del I d.C. Como toda infraestructura defensiva, en la muralla se abrían diversas puertas que permitían el acceso y la salida. Tampoco podemos olvidar diversos equipamientos complementarios que incluían varias plataformas adosadas a la cara externa de la muralla (levantadas desde el siglo I d.C.), fosos naturales y artificiales, así como numerosos torreones de planta cuadrangular y semicircular (Ruiz Bueno 2016: 55-60).

Hacia la primera mitad del siglo II d.C., el recinto amurallado de Colonia Patricia debió ser sometido a continuas reparaciones destinadas a garantizar su mantenimiento. Una de tales pudo consistir en el desmantelamiento de un tramo del muro exterior de la muralla oriental, con el fin de insertar una torre (de planta cuadrangular o rectangular) realizada mediante grandes sillares dispuestos a soga y tizón (López Rey 2002: 106). Datada de forma genérica en la segunda centuria, no descartamos que su construcción estuviese motivada por el sentimiento de inseguridad generado por las invasiones del pueblo norteafricano de los mauri hacia 170/171 y 177/178 d.C. (Ruiz Bueno y Vaquerizo 2016 : 166-168). Con independencia de la fecha exacta de dicha refectio, en las primeras décadas del siglo II d.C. debieron de continuar otras dinámicas detectadas desde al menos el siglo I d.C. Entre ellas tenemos la construcción de edificios adosados a su cara interna y externa (Ruiz Bueno 2016: 59 y 118), así como la paulatina colmatación de, como mínimo, el foso que rodeaba a la muralla por su lado noreste (Botella 1995: 241). 
Si damos el salto al callejero, a inicios de la segunda centuria el espacio intramuros contaba con una retícula urbana ortogonal en la que se diferencian claramente dos grandes sectores: por un lado, la mitad septentrional, donde tenemos constancia de insulae con unas dimensiones aproximadas de 75 por $75 \mathrm{~m}$ que estaban delimitadas por calles orientadas en sentido N-S y E-O; por otro, la mitad meridional (correspondiente con la ampliación hacia el río), con manzanas teóricas de unos $35 \mathrm{~m}$ de ancho por 70 de largo, enmarcadas por vías dispuestas eminentemente en sentido SO-NE y NOSE (Murillo 2010: 76-79). Entre las principales arterias destaca el kardo maximus, puesto que sus $22 \mathrm{~m}$ de anchura de línea de fachada a línea de fachada no tienen equivalencia en el resto de Hispania. La principal excepción es Italica, puesto que la nova urbs adrianea se dotó de un kardo maximus que, a la altura del Traianeum (Alarcón y Montero 2017), alcanzó una anchura de casi 20 m (León Alonso 1988: 13).

Al igual que en la infraestructura defensiva, en el callejero no se observan grandes cambios hacia la primera mitad de la segunda centuria. En estos momentos no hay testimonios de una relajación en las labores de limpieza de las superficies de tránsito y de las cloacas, ni tampoco de grandes proyectos urbanísticos que alterasen sensiblemente el entramado viario preexistente. Tampoco hay evidencias de episodios de privatización (parcial o total) de calzadas o aceras con motivo de la construcción o crecimiento de inmuebles aledaños a las vías. Al contrario, es muy posible que en estos momentos continuase un proceso iniciado desde, al menos, el siglo I d.C. y que consistió en la progresiva subdivisión de algunas insulae con motivo de la apertura de nuevos decumani o angiporti. De hecho, contamos con algunas calles de nueva creación fechadas de forma genérica en los siglos I-II d.C. (Hidalgo 1990: 18, Martín 2012) que podrían responder a dicha dinámica.

Finalmente, en relación con la infraestructura hidráulica, a inicios del siglo II d.C. la ciudad empleaba un variado elenco de sistemas de abastecimiento de agua limpia que incluyen pozos, cisternas y, al menos, tres acueductos construidos entre finales del siglo I a.C. y finales del I d.C. (Pizarro 2014: 61-89).

\section{ARQUITECTURA PÚBLICA Y SEMIPÚBLICA}

El estatuto de Colonia Patricia (colonia, capital de convento jurídico y caput provinciae) propició la proliferación de un considerable número de conjuntos públicos.
En su mayor parte, dichas construcciones fueron levantadas o remodeladas entre finales del siglo I a.C. y finales del I d.C., en el marco de un proceso de monumentalización que hizo de Córdoba espejo de Roma. Tras este impulso edilicio, la tónica general fue el mantenimiento y restauración de los complejos públicos existentes, así como diversos cambios en el programa decorativo de tales espacios.

\subsection{El forum coloniae}

Entre los principales espacios de la Córdoba romana destaca el foro colonial, cuya fisonomía en época altoimperial no ha podido ser bien determinada. Tan solo conocemos grosso modo la existencia de una gran plaza de unos $65 \mathrm{~m}$ de ancho por unos $130 \mathrm{~m}$ de largo, delimitada al norte por un pórtico de unos $10 \mathrm{~m}$. A esta superficie se abrirían varios edificios que incluían la basílica, que se ha venido ubicando junto al lado meridional de la plaza (Ventura 2009: 393-394, Murillo 2010: 76-79).

Si nos centramos en el período analizado, del forum coloniae y su entorno inmediato proceden diversas inscripciones honoríficas datadas de forma aproximada entre los años 71 y 200 d.C. (CIL II $/ 7$ 245, 290, 304, 370,609 , etc.), y tres fragmentos de esculturas vestidas del siglo II d.C. (dos de las cuales quizás sean de época trajanea o adrianea) que pudieron formar parte de su programa escultórico (López López 1998b: 126128, nº 81-83, López López y Garriguet 2000: 59-60). También contamos con un fragmento de cornisa en mármol blanco (h: 47, a: 86, p: 89) datado en época adrianea y que según Márquez (1998: 147, 151 y 176, $\mathrm{n}^{\mathrm{o}} 6$ ) pudo pertenecer a uno de los edificios que formarían parte del foro. A dichos elementos hay que sumar un par de piezas en mármol blanco con finas vetas grises (tal vez proconnesio) que quizás procedan del foro colonial. Se trata de un fragmento de ángulo de pilastra acanalada en tres de sus caras, así como un fragmento de fuste de pilastra acanalada (Portillo 2016: 109, $190 \mathrm{y}$ 195). Por último, contamos con una pieza más que podría resultarnos de gran interés a la hora de configurar el panorama arquitectónico del foro colonial en época adrianea.

Se trata de un fragmento de capitel corintizante elaborado en mármol blanco de grano fino, procedente del solar $n^{\circ} 16$ de la calle Cruz Conde (Córdoba). En particular, nos encontramos ante una porción del cuerpo central del kalathos de un capitel de tipo liriforme, compuesto por hojas acantizantes de perfil dentado con alternancia de hojas de agua lisas (fig. 2). El eje 


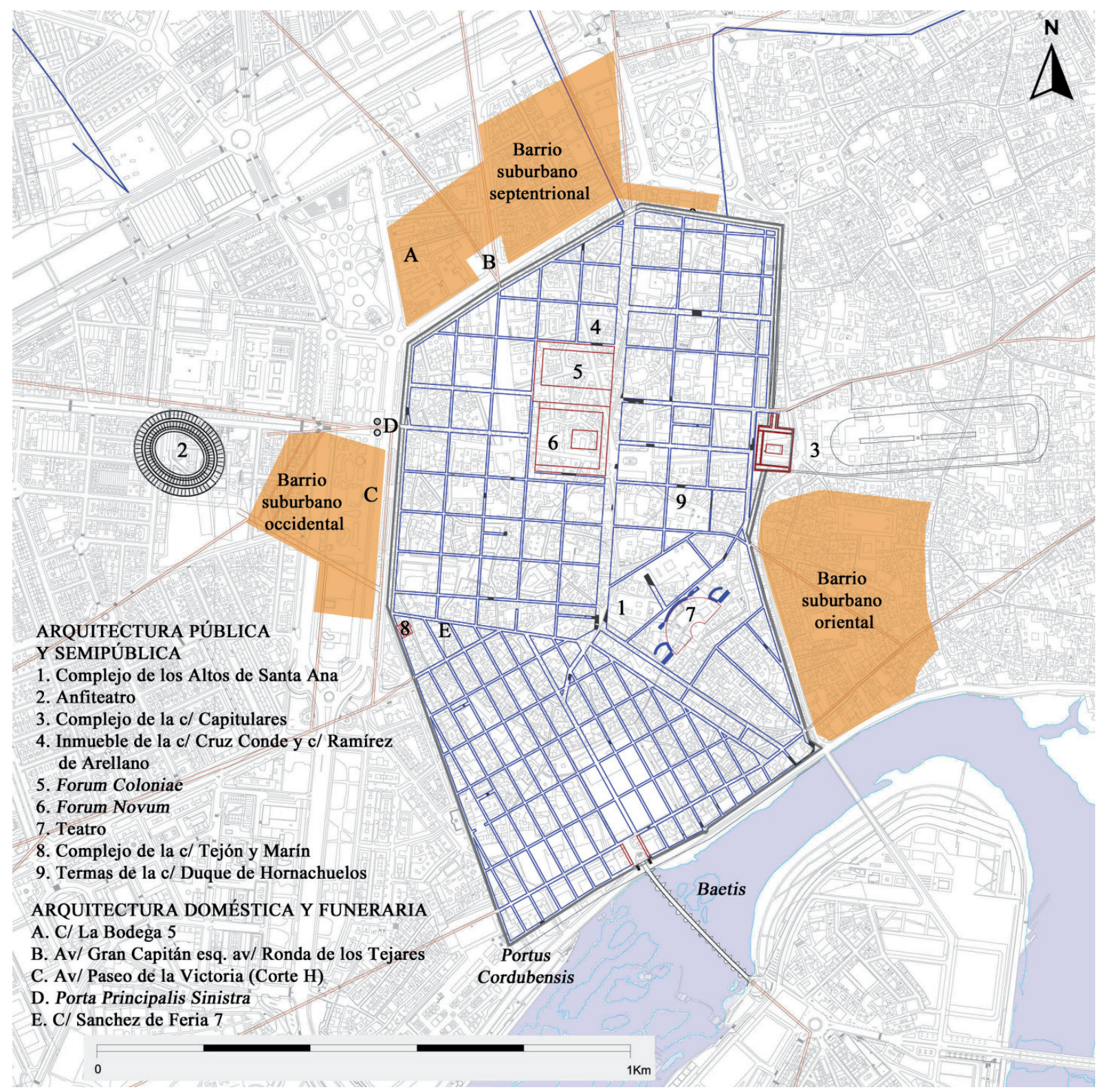

Figura 1. Plano de Córdoba hacia la primera mitad del siglo II d.C. con indicación de los principales lugares mencionados en el texto. (Modificado a partir de Ruiz Bueno 2016: planos 1-7).

del kalathos presenta un cáliz cerrado de forma puntiaguda y, en su lateral derecho, se aprecia el desarrollo de un elemento vegetal curvado que responde, muy probablemente, a un tallo que rodea a una flor pentapétala con botón central, siguiendo así el esquema habitual de esta tipología de capitel. Las hojas presentan muy poca separación del plano contiguo y poseen una nervadura central lisa y muy plana (fig. 3). La unión de las digitaciones conforma oquedades con cierta forma de gota que tienden al plano vertical, situación que puede observarse, particularmente, en la orientación de las dos concavidades que se conservan en la hoja central que precede al tallo de la flor apuntada del eje (Portillo 2018).

Este tipo de capiteles corintizantes se usaban, generalmente, en contextos privados o como decoración de peristilos o interiores y su presencia en Hispania ha sido documentada desde finales de época republicana 

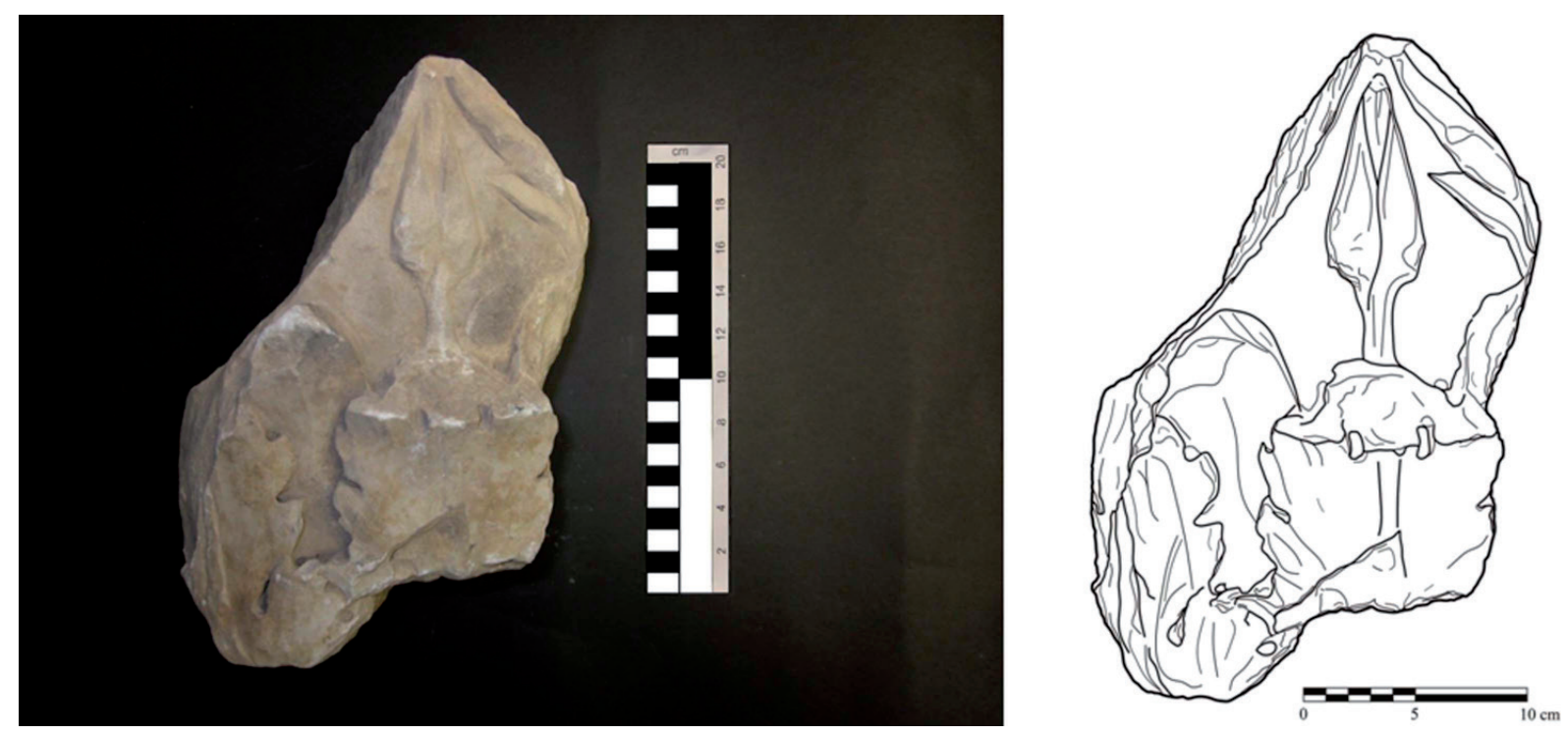

Figura 2. Fragmento de capitel corintizante procedente del solar n ${ }^{\circ} 16$ de la calle Cruz Conde (Córdoba). (Portillo 2018: 220, Cat. 98, lám. 115).
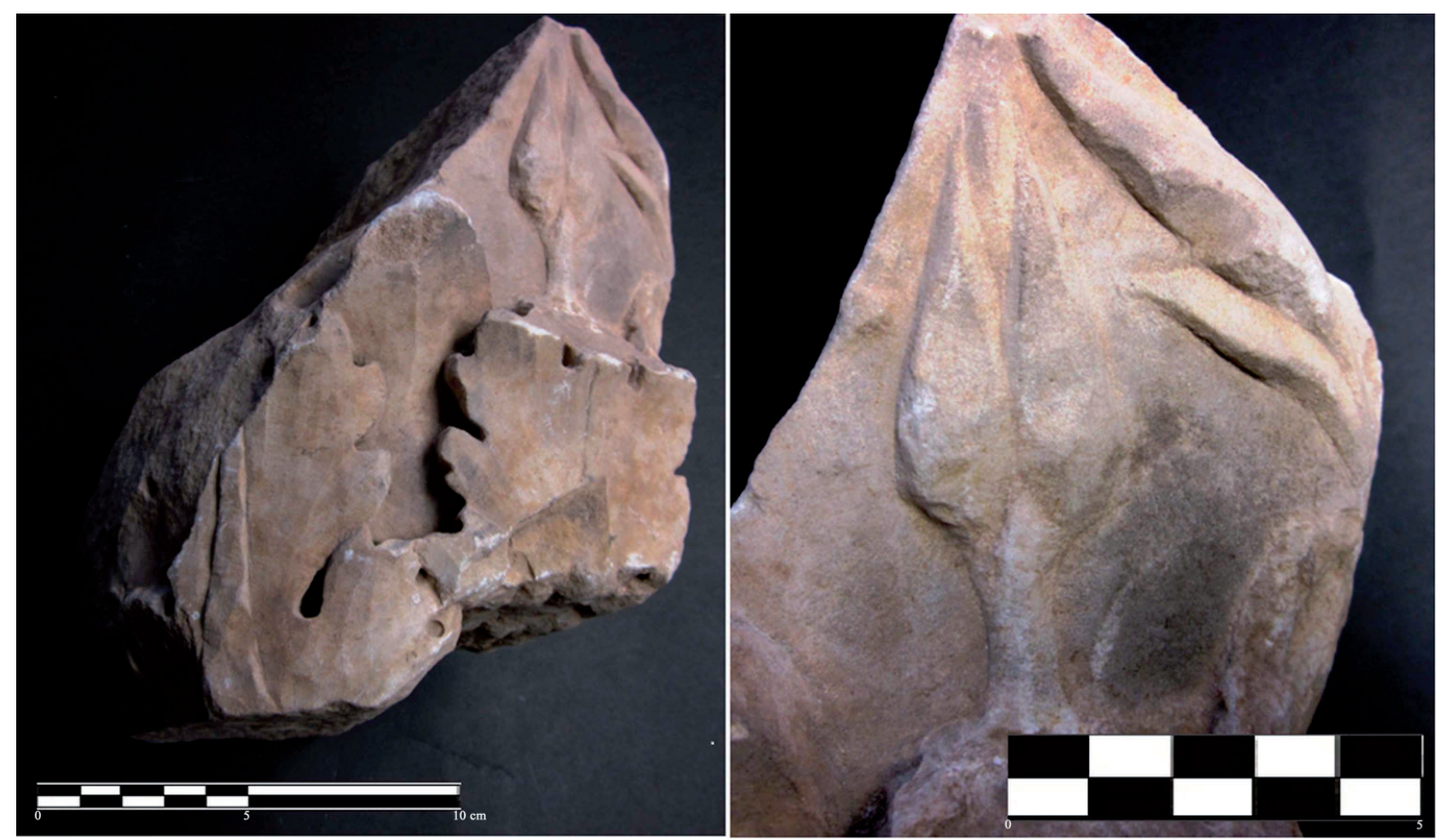

Figura 3. Detalle del capitel corintizante (Fotografías de A. Portillo).

o principios de época augustea, particularmente, en el tercio sur peninsular. Si bien es cierto que la mayoría de los capiteles de esta tipología conocidos en nuestro territorio pueden situarse en una horquilla cronológica que oscila entre mediados del siglo I d. C. hasta la tercera centuria, será en los siglos II y III cuando nos encontremos ante un periodo particularmente floreciente en la difusión de este modelo (Gutiérrez Behemerid 1983: 75-76). Por sus características estilísticas y técnicas, nos inclinamos a situar cronológicamente 
el ejemplar cordobés entre el último cuarto del siglo I d.C. y la primera mitad del siglo II d.C., remitiéndonos a los trabajos de especialistas en decoración arquitectónica como Gutiérrez Behemerid (1983), Márquez (1990, 1992, 1993, 1998, 2013, 2015), Gutiérrez Deza y Felipe (2009) o Felipe (2013), quienes han tratado de forma pormenorizada y en mayor extensión todas las particularidades de este tipo de capiteles corintizantes y piezas pertenecientes al periodo adrianeo.

Esta tipología de capiteles va a sufrir a partir de la etapa flavia una serie de variaciones que se convertirán en elementos de gran utilidad para encuadrar estas piezas cronológicamente. Una de ellas será la alternancia de hojas de acanto o acantizantes con otros tipos de hojas, como las de agua lisas o las palmetas. Otras características interesantes serán la introducción del trabajo de la labra en dos planos bien diferenciados, el difuminado de los perfiles de las hojas o el uso del trépano para marcar los contrastes de luces y sombras en las formas (Márquez 1993: 198-199).

Finalmente, la etapa adrianea va a suponer un cierto retroceso a las formas canónicas del periodo julio-claudio, una suerte de revival clasicista que, no obstante, también estará acompañado de rasgos identificativos propios. En este momento, las coronas de hojas tienden a alargarse y tomar una mayor altura que en las etapas precedentes, usando un gran número de variedades compositivas, combinaciones de diferentes tipos de hojas y elementos decorativos que ornamentan la zona libre del kalathos, obteniendo como resultado piezas de gran belleza, elegancia y originalidad.

En Córdoba conservamos otros ejemplares de esta tipología y cronología reutilizados en edificios religiosos, como es el caso de la Mezquita-Catedral o de la iglesia de San José y Espíritu Santo (fig. 4). En ambos casos nos encontramos ante el mismo modelo de capitel corintizante, de tipo liriforme y rasgos estilísticos que nos permiten agruparlos en un mismo conjunto homogéneo. Las tres piezas de la mezquita y la conservada en la citada iglesia, estudiadas magistralmente por Márquez (1993) y Peña (2010), comparten tipología, proporciones (unos $47 \mathrm{~cm}$ de altura), estilo (hojas de siete lóbulos digitados con un acusado carácter espinoso, que alternan con hojas de agua lisas y cuya nervadura central es bastante plana, con la particularidad de contar con pequeños canales diagonales contrapuestos labrados en toda su longitud) y supuesto origen. En este sentido, tanto Márquez (1993: 199) como Peña (2010: 152-153), han defendido la procedencia emeritense del grupo, siendo su similitud con un ejemplar reutilizado en el pórtico neogótico de la alcazaba de Mérida, más que evidente. Según estos autores, el grupo conservado en Córdoba podría haber llegado a la ciudad entre los años 835 (fecha de inicio de construcción de la alcazaba) y el 848 (cuando arrancan las obras de ampliación de la Mezquita por parte del emir 'Abd al-Raḥman II).

A pesar de la fragmentación y deterioro del ejemplar procedente de la calle Cruz Conde, podemos comprobar que se trata del mismo tipo de capitel que el grupo reaprovechado, con determinadas diferencias, como la falta de los canales diagonales de la nervadura central o un perfil dentado mucho más marcado en las digitaciones. Las pequeñas variaciones se perciben incluso si comparamos el ejemplar de la iglesia de San José, donde se aprecia una talla mucho más plana, con formas menos contrastadas, y los conservados en la Mezquita-Catedral, donde se puede observar un mayor uso del trépano, con formas más definidas y oquedades más profundas que generan figuras de mayor relieve. Esta situación es bien perceptible en las dos flores pentapétalas localizadas en la zona libre del kalathos o en la elaboración del perfil dentado del acanto, mucho más acusado en el caso de los capiteles conservados en la Mezquita-Catedral.

Estas modificaciones son relativamente corrientes en el trabajo de un taller, donde intervienen distintos factores que repercuten, de forma directa, en el acabado final de las obras, como la visibilidad de la cara de la pieza en su ubicación definitiva, el grado de experiencia y pericia técnica del operario que ejecuta la obra o la calidad y cualidades del material empleado. No olvidemos que, una vez organizada la tarea en el taller y teniendo claro qué tipo de trabajo se va a realizar, es muy habitual que algunas zonas de las piezas, aquellas que serán las menos visibles, reciban un trabajo más somero, realizando una especie de esbozo general y un trabajo formal mucho menos detallado que en las caras de la pieza que quedarán expuestas a las zonas más transitadas y visualmente accesibles. Tampoco será igual el trabajo ejecutado por un aprendiz u operario con poca experiencia, que la elaboración que puede proporcionar un maestro en estas labores, quien cuidará mucho más el detalle y el acabado final. Por tanto, la mano que realiza la tarea compromete el aspecto definitivo de la obra. Y por último se encuentra la cuestión de la naturaleza del material, características como su dureza, maleabilidad, color, brillo, etc. ya que afectan directamente a la talla de la obra, sea en sentido positivo como en negativo.

Lamentablemente, el estado fragmentario de la pieza de la calle Cruz Conde nos impide poder afirmar 


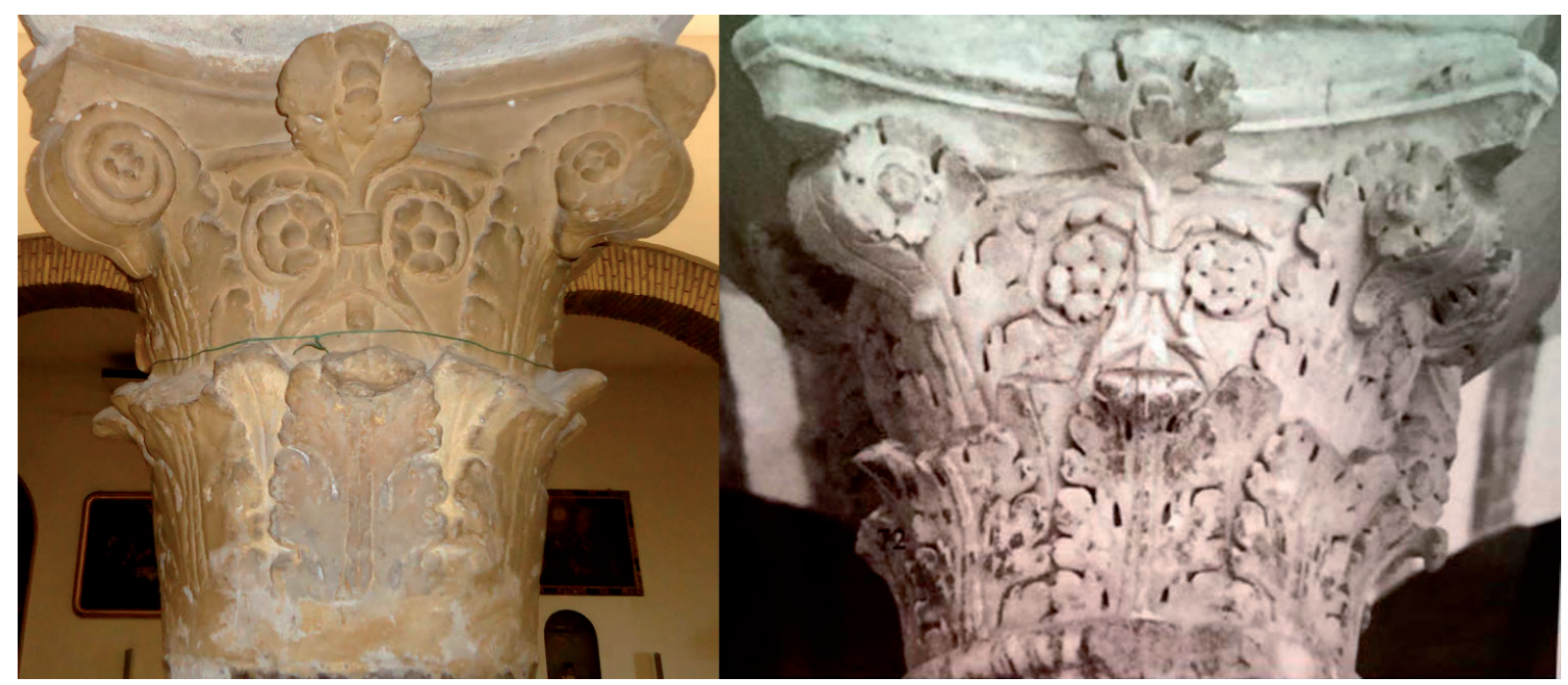

Figura 4. Izquierda. Capitel corintizante romano reutilizado en la iglesia de San José y Espíritu Santo (Córdoba). (Fotografía de M.D. Ruiz). Derecha. Capitel corintizante romano reutilizado en la ampliación de Abd al-Rahman II de la Mezquita (Córdoba).

(Peña 2010: 283, lám. 41, $\mathrm{n}^{\circ}$ 72). La altura de ambas piezas es de $47 \mathrm{~cm}$.

con seguridad que este capitel formaba parte del citado grupo reutilizado, cuyo origen pudo ser, en realidad, plenamente cordobés. No obstante, dadas sus semejanzas estilísticas y proporcionales (el fragmento cuenta con unas medidas de $19.5 \mathrm{~cm}$ de altura, $15 \mathrm{~cm}$ de anchura y $11.5 \mathrm{~cm}$ de profundidad, por lo que la pieza completa podría alcanzar fácilmente los 47 o $48 \mathrm{~cm}$ de altura como los ejemplares reutilizados), habría que considerarlo, al menos, como una muestra más del gusto y hábito de uso de esta interesante tipología de capiteles corintizantes como elemento decorativo de algún espacio, de carácter privado o semiprivado, que formaría parte del foro colonial de Colonia Patricia, muy probablemente, en el periodo adrianeo.

\subsection{El forum novum}

Inmediatamente al sur del foro colonial se levantó el forum novum (Portillo 2018). Con dicho término se denomina un impresionante conjunto monumental erigido en el primer tercio del siglo I d.C. y que consistía, a grandes rasgos, en una plaza porticada en cuyo centro se construyó un gran templo octástilo en mármol lunense con una anchura de fachada de $29.6 \mathrm{~m}$ y una altura de c $30 \mathrm{~m}$ (Portillo 2016: 53 ss.). El templo, dedicado a divus Augustus, no permaneció ajeno al paso del tiempo y es muy probable que fuese restaurado hacia la primera mitad del siglo II d.C., cuando se han fechado tres fragmentos de coronamiento de arquitrabe. En los tres casos, las particularidades de su talla y el estilo de sus molduras parecen corresponder a las propias del periodo trajano-adrianeo (Portillo 2015: 76-81).

Además de dichas piezas, contamos con un elemento de gran interés que podría ser testimonio de la reforma del forum novum o bien, sencillamente, parte integrante de la imagen arquitectónica de este espacio público durante la primera mitad de la segunda centuria. En este caso, se trata de un fragmento de capitel jónico que genera ciertas dudas para otorgarle una precisa datación, motivo por el cual hemos optado por incorporarlo en estas páginas (figs. 5 y 6). La pieza, recuperada en la céntrica calle Morería, fue registrada en los fondos del Museo Arqueológico y Etnológico de Córdoba en 1911, donde se conserva desde entonces, perteneciendo a la citada institución las imágenes que publicamos. Se encuentra elaborada en mármol blanco de grano fino y alcanza unas proporciones de $17.5 \mathrm{~cm}$ de altura y $14 \mathrm{~cm}$ de anchura. El cojinete está formado por una serie de hojas de acanto de cinco lóbulos y nervadura central desarrollada con canal de sección en V, que alternan con hojas de agua lisas. Las puntas de las hojas de acanto adoptan un aspecto lanceolado, generando oquedades en forma de gota con una ligera tendencia a la verticalidad. En el lateral del extremo del bálteo, se desarrolla una decoración vegetal en torno a un botón central formado por una flor tetrapétala, que genera una voluta en la que encontramos una flor alargada con una sarta de granos o semillas (Portillo 2018: 236-237, cat. 105, lám. 124-125). 

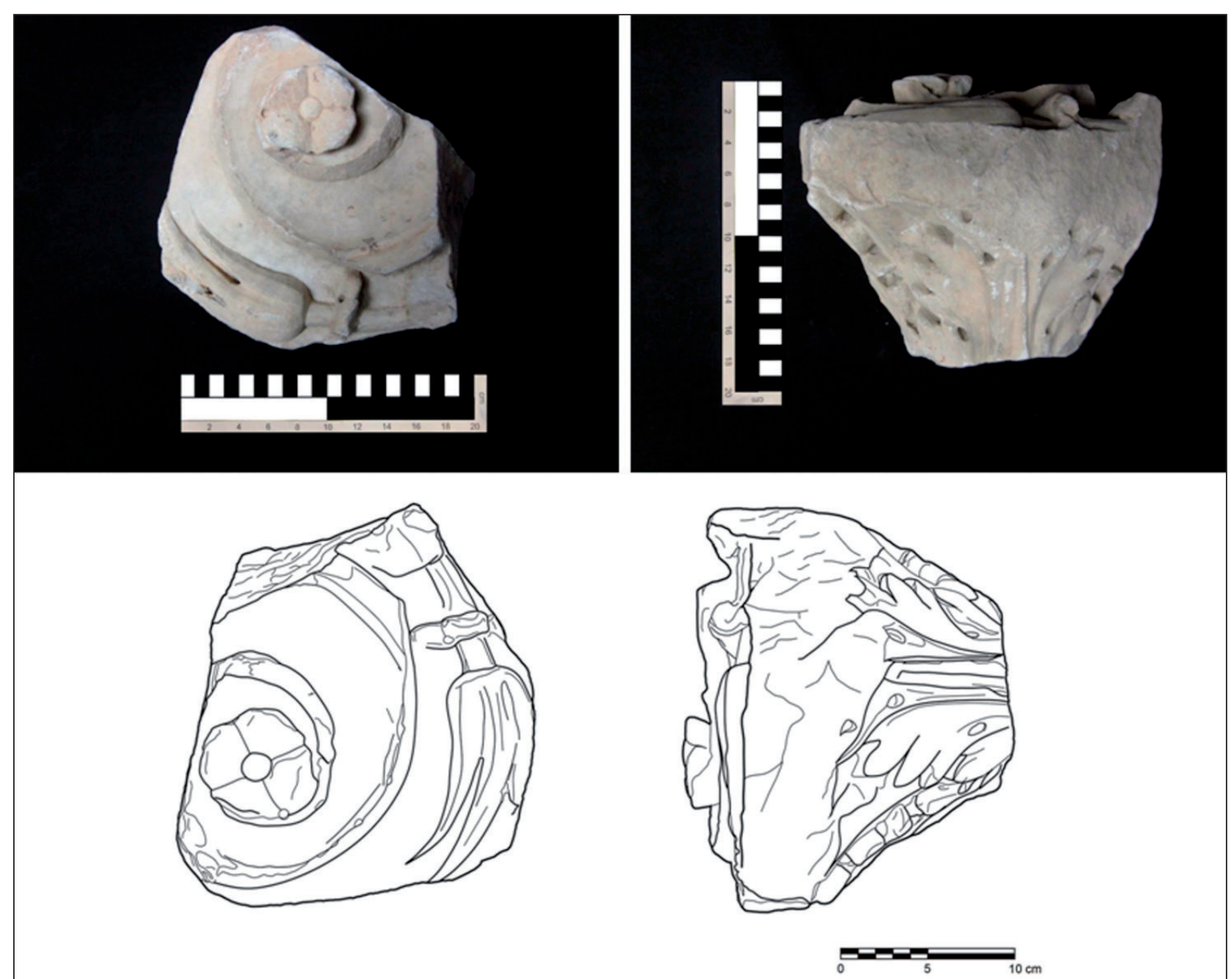

Figura 5. Fragmento de capitel jónico procedente de la calle Morería (Córdoba). (Portillo 2018: 236-237, cat. 105, lám. 124-125).

La complejidad de esta pieza radica en la presencia de ciertos rasgos pertenecientes a dos etapas alejadas en el tiempo conviviendo en la misma superficie. La labra de las nervaduras, el aspecto lanceolado de las hojas y la plástica general de la pieza nos remitirían directamente al periodo julio-claudio. Sin embargo, encontramos un par de signos muy característicos de la etapa trajano-adrianea que llaman poderosamente nuestra atención. La habitual combinación de hojas de acanto y hojas de agua y, sobre todo, la presencia del cáliz semicerrado en el extremo del canal de la voluta, son rasgos más acordes a la praxis decorativa de la primera mitad de la segunda centuria de nuestra era (Márquez 1998: 125), y que podemos encontrar en edificios de esta etapa. Las volutas de ejemplares como los capiteles compuestos procedentes del Traianeum de Italica (Rodero 2002: 90, Becerra 2019: 981) o los jónicos que decoran las termas mayores de la Villa Adriana en Tívoli, dan muestra de ello.

Por si fuera poco, Márquez (1998: 259, $\mathrm{n}^{\circ}$ 522) identifica un segundo fragmento que correspondería a esta misma pieza cordobesa y que se conserva en el Museo Arqueológico cordobés. En esta porción, la presencia de las hojas imbricadas en la zona central del balteus nos muestra otro elemento decorativo muy usado en esta etapa, que sería un dato más que sumar a la posibilidad de considerar esta pieza como una producción adrianea. Como ya hemos señalado, el gusto por la estética julio-claudia durante la primera mitad del siglo II d. C. será una constante en la plástica que no podemos eludir, por lo que no descartamos que este ejemplar hubiese sido elaborado en la etapa adrianea siguiendo los patrones artísticos marcados por el princeps, junto con determinadas innovaciones y hábitos 


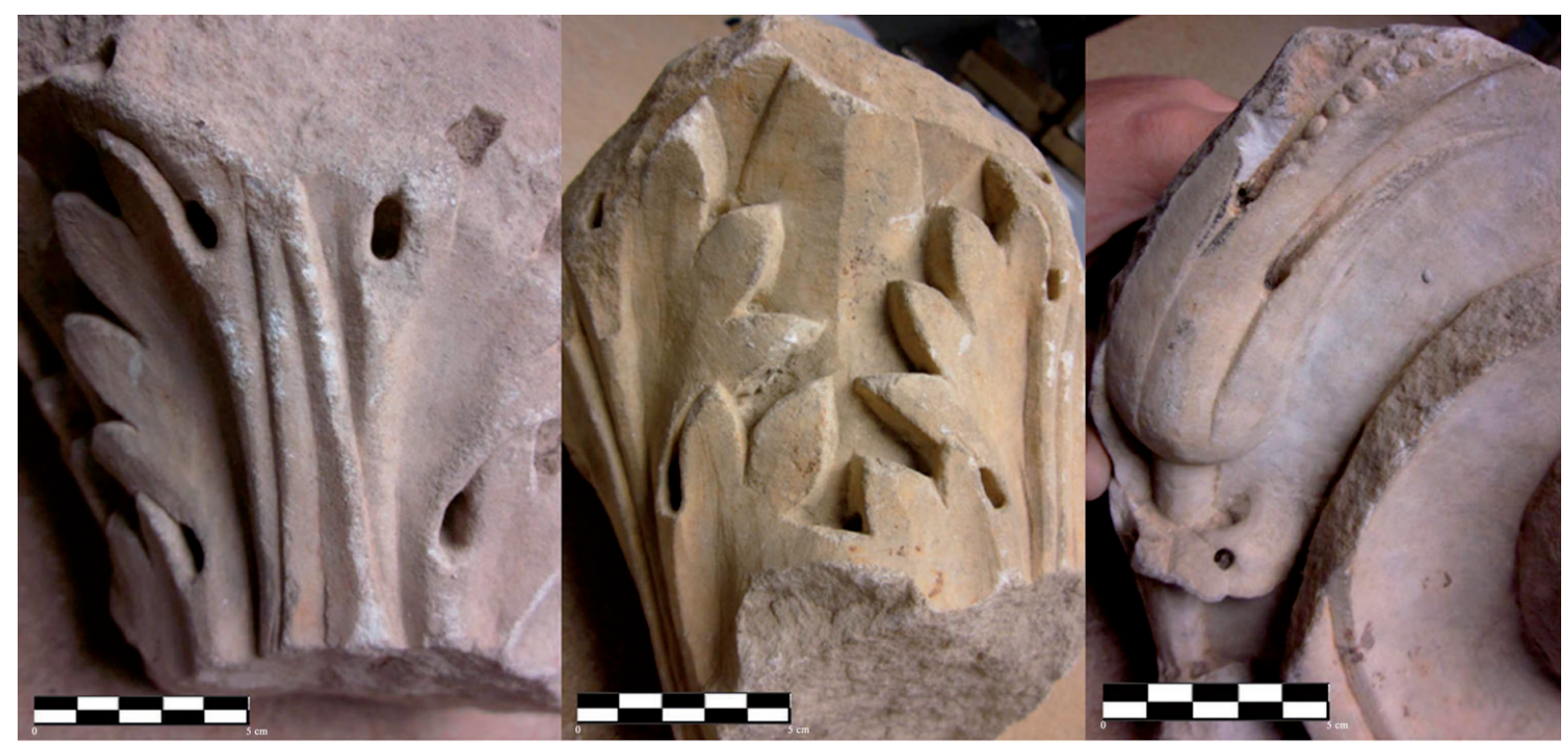

Figura 6. Detalles de fragmento de capitel jónico procedente de la calle Morería (Córdoba). (Fotografías de A. Portillo).

estilísticos propios del momento, en consonancia con las prácticas y formas decorativas coetáneas.

\subsection{Otros espacios monumentales}

Si dejamos a un lado el núcleo integrado por el foro colonial y el forum novum, otro complejo monumental cordobés destacado es el situado en la zona de los Altos de Santa Ana, del que prácticamente solo conocemos una plaza relacionada con un cercano edificio público de función ignota (López López 1998a: 126 y 231-232). Desde un punto de vista funcional, se ha sugerido que nos encontremos ante una posible área sacra vinculada al culto imperial en su nivel local (Garriguet 2002: 128). Con independencia de su uso exacto, de este sector proceden varios hallazgos escultóricos y epigráficos, que incluyen un fragmento de escultura femenina en mármol blanco datada entre finales de época trajanea y principios de época adrianea (López López 1998b: 87-89, n 56).

A escasa distancia del complejo de los Altos de Santa Ana se levantó el teatro de Colonia Patricia. Desde su construcción con anterioridad al año 5 d.C., su decoración arquitectónica, escultórica y epigráfica fue renovada periódicamente. Por su especial entidad destaca una reforma fechada en época antonina y cuyo verdadero alcance es desconocido. A ella se han adscrito varios fustes labrados en mármol verde antico (coronados por capiteles compuestos de mármol proconnesio); un retrato del emperador Antonino Pío (Garriguet 2002: 37-40), y cinco fragmentos de relieves (en mármol o caliza marmórea blanca) datados a finales del siglo I - inicios del II d.C., y que representan alegorías femeninas de las provincias y pueblos que componían el Imperio. Ante la magnitud del programa, se ha defendido que el único lugar que pudo haberlo albergado fue la porticus in summa cavea, confirmando el carácter del teatro como espacio de culto imperial (Márquez 2002: 256-260).

Además del teatro, Córdoba contaba en estos momentos con otros dos importantes edificios de espectáculos públicos extramuros. Uno es el anfiteatro, situado a poniente de la ciudad y en cuyas inmediaciones se situó una necrópolis gladiatoria que continuó acogiendo sepulturas de dichos combatientes a lo largo de la segunda centuria, tal y como se deduce a partir de la epigrafía funeraria (Sánchez Madrid y Vaquerizo 2010: 500). En cuanto al circo, este formaba parte de un gran complejo monumental aterrazado relacionado con el culto imperial. Conocido bajo el nombre de conjunto de la calle Capitulares (entre otras denominaciones) se distribuía en tres terrazas. La terraza superior (in urbe), estaba presidida por un templo hexástilo y pseudoperíptero; la intermedia consistía en una gran plaza, y la inferior estaba ocupada por el circo (Murillo 2010: 8487, Gutiérrez Deza 2016). Aun cuando es evidente que dicho complejo estaba en pleno uso en la primera mitad del siglo II d.C., no contamos con testimonio epigráfico, escultórico o arquitectónico alguno adscrito al 
citado marco temporal. Dicha casuística es extrapolable a otros espacios como el conjunto religioso de la calle Tejón y Marín, en uso hasta el siglo IV y donde no disponemos de evidencias arqueológicas adscritas a la segunda centuria (Portillo y Ruiz-Bueno 2017).

No quisiéramos finalizar este apartado sin hacer referencia a varias construcciones cuya propiedad pudo ser pública, semipública o incluso privada. En primer lugar, tenemos un establecimiento termal de titularidad y uso público, o bien de propiedad y gestión privada, pero abierto al público, localizado en calle Duque de Hornachuelos $n^{\circ} 8$. A falta de un estudio en profundidad de su planta y organización interna, sabemos que parte de su programa escultórico puede datarse en época adrianea. Se trata de un conjunto estatuario en mármol blanco de grano medio-grueso y cristalino (fig. 7), compuesto, como mínimo, por una escultura de Eros, un torso masculino desnudo y un torso masculino con clámide. En el momento de su hallazgo, todas ellas se encontraban depositadas en la piscina del frigidarium de las termas (Garriguet 2013: 384-394).

En segundo lugar, en varios solares situados inmediatamente al norte del foro colonial (calle Cruz Conde $n^{\circ}$ 14-20 y calle Ramírez de Arellano no 5-7), fue descubierto en la década de 1940 un gran inmueble del que hay evidencias de varias estancias articuladas alrededor de un peristilo y que, en algunos casos, tuvieron un uso termal (Ruiz Bueno 2016: 89). Más difícil es establecer la finalidad exacta del edificio, si bien, las hipótesis que se barajan es que nos encontremos ante unos baños públicos de gestión privada, un balneum doméstico privado o, incluso, un collegium (Ventura 1996: 110-111, 2009: 393). Respecto a su cronología, es posible que estuviese en pie desde, al menos, época julio-claudia, siendo su aparato decorativo remodelado en la primera mitad del siglo II, cuando se ha datado (mediante análisis estilísticos) un suelo de opus tesellatum que pavimentaba uno de los ambientes (Moreno 1996: 106) y que para Pérez Olmedo (1996: 107), su «realización en época adrianea parece bastante coherente»

En tercer y último lugar tenemos un edificio cordobés de posible cronología adrianea, pero de ubicación desconocida, y del que conocemos diversos materiales reutilizados en la primera fase constructiva de la Mezquita Aljama, levantada entre los años 786 y 787 d.C. En total ha podido identificarse un conjunto homogéneo (en cuanto a tipología, material y dimensiones) compuesto por 8 basas áticas lisas (en mármol blanco), 10 capiteles corintios (en el mismo material) y 17 fustes lisos (de lumachella carnina) que pertenecieron a una construcción que pudo tratarse de un pórtico, de un templo, o incluso, del peristilo de una casa (Peña 2003).

\section{ARQUITECTURA DOMÉSTICA Y PRODUCTIVA}

En cuanto a la edilicia privada (fig. 1), la limitada y dispar documentación arqueológica del espacio intramuros procede en gran medida de domus unifamiliares, que ocuparon buena parte de la superficie in urbe. Si bien es cierto que debieron existir otras edificaciones más modestas, la información actual se limita en gran medida a tabernae que probablemente combinaron la función económica con la habitacional. La principal excepción parece haber sido la fachada meridional de la ciudad, donde se dispuso un barrio artesanal y comercial que aprovechó la cercanía del río Baetis y del portus cordubensis (León Pastor 2010).

La sistematización de antiguos y nuevos hallazgos ha permitido conocer un variado elenco de viviendas preexistentes que, con mayor o menor seguridad, se encontrarían habitadas hacia la primera mitad del siglo II d.C. (Ruiz Bueno 2016: 90-97). A ellas hay que sumar otros inmuebles de uso residencial cuya construcción se ha datado de forma genérica en la segunda centuria (Vargas et al. 2010: 380-381, Lázaro 2013: 78$79)$, sin olvidar tampoco una vivienda de época tiberiana remodelada en el siglo II d.C., cuando tuvo lugar tanto una renovación de su aparato decorativo (pinturas parietales y pavimentos musivos), como una reorganización espacial que afectó, como mínimo, a un peristilo y al tránsito entre determinadas estancias (Moreno Almenara e.p.). A dichas evidencias hay que sumar un mosaico con decoración geométrica fechado en la primera mitad del siglo II d.C. (mediante comparaciones estilísticas), exhumado en calle Sánchez de Feria $n^{0} 7$ y adscrito a una posible área residencial (Moreno González 1996: 50). No obstante, al tratarse un hallazgo antiguo (1977) ignoramos si perteneció a una domus construida o remodelada en estos momentos.

Aun cuando en la primera mitad de la segunda centuria buena parte del espacio intramuros se encontraba ocupado por construcciones públicas y privadas, lo cierto es que tenemos constancia de, como mínimo, un solar (situado en la ampliación de la urbe republicana hacia el río) que no fue urbanizado hasta la segunda mitad del siglo II o ya el siglo III d.C. cuando aconteció la construcción de una vivienda levantada directamente sobre el nivel geológico (Montejo 1998: 3033). Dicha circunstancia cobra sentido si tenemos en 


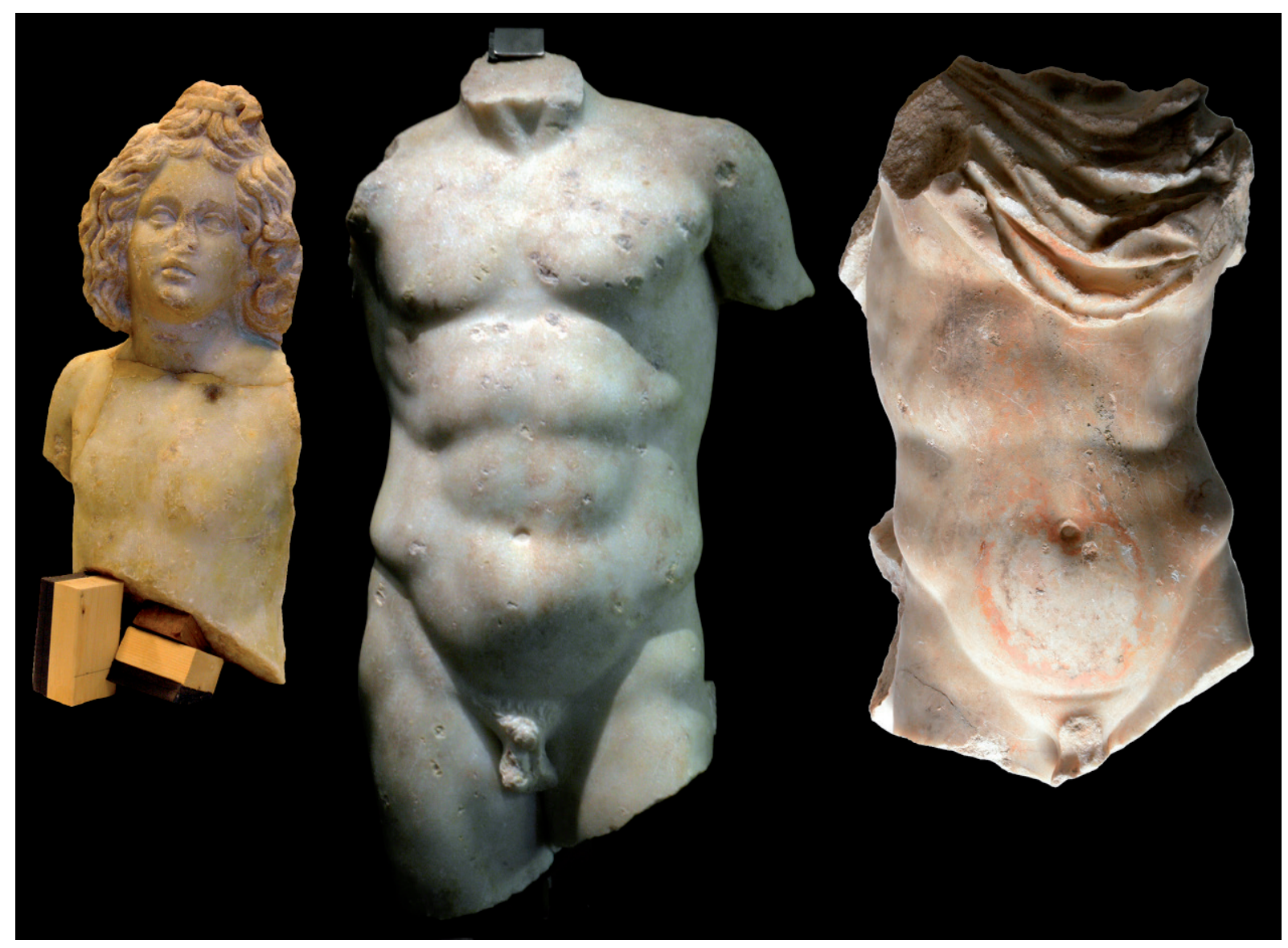

Figura 7. Estatuas ideales descubiertas en calle Duque de Hornachuelos 8. A la izquierda, escultura de Eros; en el centro y a la derecha, representaciones de dos jóvenes atletas. La altura conservada de las piezas ronda los $0.60,0.87$ y $0.73 \mathrm{~m}$ respectivamente. (Fotografías de J.A. Garriguet).

cuenta que desde época tardorrepublicana y augustea, pero sobre todo a partir de época flavia, la ciudad creció más allá de sus murallas en forma de barrios suburbanos. Se trata de áreas artesanales, comerciales y eminentemente residenciales ubicadas junto a las principales vías que partían de las puertas de entrada y salida a la ciudad.

En el marco temporal en el que nos movemos, los distintos barrios se encontraban en un proceso de crecimiento y expansión materializado en la edificación de inmuebles de diversa índole. Si comenzamos por el barrio extramuros occidental, en avenida Paseo de la Victoria (Corte H) fue exhumada una domus de la que conocemos cinco espacios diferentes interpretados como almacenes. El inmueble, construido a finales del siglo I d.C. o en las primeras décadas del siglo II d.C., se levantó sobre una zona productiva previa (Cánovas 2010: 424, Vargas 2010: 454).
En cuanto al barrio suburbano septentrional, el registro arqueológico refleja la construcción, en un momento indeterminado del siglo II d.C., de diversas viviendas e instalaciones industriales sobre áreas funerarias previas (Ibáñez 1990, Moreno González 1996: 199, Molina 2017). Especialmente significativo es un mosaico con decoración geométrica (de $5 \mathrm{~m}$ de largo por 3,50 de ancho), que ha sido datado en la primera mitad del siglo II d.C. mediante análisis estilísticos (Moreno González 1996: 165). El pavimento fue descubierto durante una Intervención Arqueológica de Urgencia llevada a cabo en calle La Bodega $\mathrm{n}^{\circ} 5$ donde, en el marco de una posterior remoción de tierras, se localizó (a mayor profundidad) un monumento funerario adscrito a la primera mitad del siglo I d.C. (Vaquerizo 2001: 141-144, Ruiz Osuna 2007: 78-81). Más polémica es la datación de un mosaico perteneciente a un triclinium, o a una sala de representación o prestigio de 
una vivienda, que también debió de instalarse en una zona con una ocupación funeraria previa (Vaquerizo 2001: 140-141). En este caso nos encontramos ante un pavimento musivo de tema circense fechado en la primera mitad del siglo II d.C. (Blázquez 1993: 427-428) o ya en el siglo III d.C. (Moreno González 1996: 206).

El tercer y último barrio suburbano conocido se extendía al sureste de la urbe, donde las intervenciones arqueológicas apuntan hacia un irregular uso del espacio en el siglo I d.C. (con zonas desocupadas y otras construidas de forma un tanto desordenada), frente a un siglo II d.C. caracterizado por una ocupación más consolidada y definida (Rodero 2004: 194). En esta centuria ha sido fechada una domus superpuesta a varias estructuras anteriores de uso industrial (Molina y Sánchez 2003: 358), además de un mosaico con cabeza de Medusa perteneciente a una vivienda construida o remodelada en estos momentos (Moreno González 1996: 220). También es digna de mención una oficina oleícola del siglo I d.C. inmersa en varias transformaciones a lo largo de la segunda centuria (León Pastor 2010: 66).

Además de los barrios suburbanos, al suroeste de la urbe debió de ubicarse el complejo portuario de la ciudad, cuya fisonomía y configuración sigue sin ser bien conocida. Tan solo podemos señalar el descubrimiento de un edificio adosado muy probablemente a la cara externa de la muralla, y que posiblemente estuvo destinado a satisfacer las actividades sociales, económicas o comerciales del fondeadero. Tras levantarse hacia mediados del siglo I d.C., una de sus estancias fue remodelada hacia el segundo tercio del siglo II d.C., cuando pasó a estar ornamentada mediante un mosaico con motivos de carácter marino (León Muñoz et al. 2008, Ruiz Osuna y Ruiz 2018).

Finalmente, a una mayor distancia de la ciudad tenemos evidencias de varios establecimientos suburbanos y periurbanos aislados de carácter doméstico y/o productivo que, en determinados casos, pudieron haber funcionado como villae. Por lo general, se trata de conjuntos ya existentes sometidos a algunas reformas y remodelaciones puntuales fechadas de forma genérica en el siglo II d.C. (Ortiz 2011) y que en algunos casos supusieron un incremento de su uso agrícola e industrial (García Matamala 2010: 446-447; Vaquerizo 2014: 32-33).

\section{ARQUITECTURA FUNERARIA}

Los estudios llevados a cabo por Ruiz Osuna (2007, 2010) han puesto de relieve varios rasgos que caracterizaron a la arquitectura y topografía funeraria de la ciudad hacia la primera mitad del siglo II d.C. (fig. 1). En este marco temporal hay evidencias de varias dinámicas que incluyen la intensa actividad funeraria en los suburbia occidental y septentrional, así como la inutilización de buena parte de las necrópolis aledañas a las principales puertas de entrada y salida debido al crecimiento de los citados barrios suburbanos. Es el caso de un sector privilegiado situado en las inmediaciones de la antigua Porta Principalis Sinistra (Puerta de Gallegos), cuya funcionalidad funeraria quedó anulada en la segunda mitad del siglo II d.C. con motivo del crecimiento del barrio suburbano occidental (Murillo et al. 2002: 263-268). La principal excepción parece haber sido una necrópolis emplazada junto a uno de los accesos abiertos en el lienzo septentrional de la muralla. Así, del entorno de la avenida del Gran Capitán esquina con Ronda de los Tejares, proceden dos inscripciones en las que se recoge la dedicación de honores funerarios por parte de la Colonia a Titus Flavius (CIL II ${ }^{2} / 7$ 290) y Quintus Caecilius (CIL II ${ }^{2} / 7$ 303), habiéndose fechado el primer epígrafe entre 131 y 170 d.C. y el segundo entre 131 y 150 d.C. (Ruiz Osuna 2007: 140).

En cuanto a la arquitectura funeraria, al igual que ocurre en la edilicia pública, en la primera mitad de la segunda centuria parece disminuir la fiebre constructiva en lo que se refiere a grandes monumentos funerarios. Las estelas disminuyen considerablemente en número, mientras que los bloques paralepípedos y las placas de gran formato comienzan a escasear (Ruiz Osuna 2010: 249). Entre las evidencias de monumentalización funeraria datadas en la primera mitad del siglo II d.C., destaca un togado masculino en mármol blanco que luce además los calcei de rango ecuestre, lo que apunta hacia un personaje de elevado prestigio (López López 1998b: 62-63, n 34, Ruiz Osuna 2007: 117-118).

\section{CONCLUSIONES}

El advenimiento de la dinastía antonina, y de forma más concreta la llegada al poder del emperador Adriano, no parecen haber tenido un profundo impacto en la arquitectura y urbanismo de Colonia Patricia. La documentación actualmente disponible atestigua escasas alteraciones o novedades sustanciales en la infraestructura defensiva, viaria e hidráulica de la ciudad, puesto que la tónica general fue el mantenimiento del recinto amurallado, de las vías, de las cloacas y de los acueductos preexistentes. Dicha circunstancia no resulta extraña si tenemos en cuenta que «cuando las ciudades 
logran dotarse de las obras de infraestructura y de los edificios necesarios para el desarrollo de la vida urbana los trabajos de construcción experimentan un fuerte retroceso y son sustituidos por labores menores de reparación y de mantenimiento» (Melchor 1993: 148-149).

La citada reflexión es extensible a la arquitectura pública del caput provinciae bético, donde no ha sido posible detectar programa edilicio alguno de gran envergadura, a excepción de la reforma de la porticus in summa cavea del teatro en un momento indeterminado de época antonina y la restauración del templo del forum novum en las primeras décadas del siglo II d.C. Más difícil es precisar el verdadero alcance de las actuaciones llevadas a cabo en el foro colonial, donde es posible que se construyesen o renovasen algunos de los edificios que lo integraban.

En los tres casos, la ausencia de testimonios epigráficos nos impide determinar si nos encontramos ante actuaciones de carácter imperial. Pese a dicho obstáculo, no descartamos que la posible refectio del templo del $f_{o}$ rum novum responda quizás al paso de Trajano o Adriano por Hispania. Se trata de una hipótesis muy sugerente si tenemos en cuenta el panorama existente en Tarraco, donde tras el análisis de la documentación arqueológica y textual disponible, se ha sugerido la posibilidad de que la basílica del foro colonial, y quizás también alguna que otra obra pública, fuese restaurada por Adriano durante su visita a la capital de la Tarraconense en el invierno de 122 d.C. (Mar et al. 2015: 264-265).

Más evidente resulta la influencia indirecta de Trajano y Adriano en la decoración arquitectónica y escultórica cordobesa, tanto de carácter público como privado, puesto que la llegada al poder de ambos trajo consigo una eclosión artística caracterizada por la combinación del clasicismo con los influjos orientales. Dicha circunstancia no solo repercutió en Italica, sino también en otros puntos de la provincia bética, incluyendo el caput provinciae. En este último destaca su incidencia en ámbitos como la decoración arquitectónica (Márquez 1998), incluyendo la funeraria (Ruiz Osuna 2007: 139-140); los capiteles (Márquez 1993: 117-118), o la estatuaria (López López 1998: 155, Garriguet 2013: 394). En relación con esta última, a los testimonios previamente citados habría que sumar la reciente identificación de un posible retrato de Adriano conservado en el actual Palacio de Viana (Córdoba). Pese a tratarse de un fragmento escultórico descontextualizado, es posible que «proceda del entorno de Córdoba» (Garriguet 2018: 586).
Si damos el salto a la edilicia doméstica, la limitada y desigual información actualmente disponible impide en muchos casos precisar si nos encontramos ante viviendas construidas o remodeladas en la primera mitad del siglo II d.C. No obstante, tras comparar Córdoba con el panorama existente en otras ciudades hispanorromanas (Romero 2016: 349-354), parece que la segunda centuria fue un momento caracterizado en gran medida por la construcción de algunos edificios de nueva planta $\mathrm{y}$, sobre todo, por la remodelación de inmuebles preexistentes, donde los principales cambios afectaron a la distribución espacial y al aparato decorativo. Acerca de este último punto, en el caso de Córdoba contamos con varios estudios centrados en el análisis de capiteles y mosaicos (Márquez 1993), Moreno González 1996, Ruiz Osuna y Ruiz 2018), que debieron emplearse eminentemente en edificaciones domésticas. En el caso de los capiteles, de los más de 320 ejemplares conocidos a principios de la década de 1990, alrededor de un $20 \%$ se han datado en la primera mitad del siglo II d.C., manteniéndose dicho porcentaje estable (22\%) en la segunda mitad de dicha centuria. Por el contrario, solo unos pocos mosaicos han podido datarse con precisión hacia la primera mitad del siglo II d.C. Dicho dato contrasta con los pavimentos musivos fechados (en la mayoría de los casos mediante análisis estilísticos) entre mediados del siglo II e inicios del III d.C., puesto que a este marco temporal se han adscrito casi el $43 \%$ de los más de 200 mosaicos identificados hasta la fecha.

El auge de la musivaria cordobesa entre los comedios de la segunda centuria e inicios de la tercera no fue el único rasgo que definió dicho período. Frente a una primera mitad del siglo II d.C. que podríamos calificar en muchos aspectos como "continuista", el marco temporal de apenas 50-60 años que se extendió desde mediados del siglo II d.C. hasta el fin de la dinastía severiana influyó decisivamente en la topografía y arquitectura de Colonia Patricia. Entre algunas de las novedades más reseñables, destaca la privatización parcial de algunos de los principales ejes viarios de la urbe (kardo y decumano máximos), la profunda remodelación de varias áreas cultuales existentes (complejo de los Altos de Santa Ana y conjunto de la calle Capitulares), el abandono del circo y su conversión en cantera (Ruiz Bueno 2018: 39-40 y 80-83), la posible remodelación del sector portuario cordobés en el marco de la política intervencionista de Septimio Severo (León Pastor 2010: 62), o la gran producción epigráfica de carácter funerario, puesto que entre mediados del siglo II d.C. y principios del siglo III d.C. se han datado la mayoría de los epígrafes funerarios romanos localizados 
en Córdoba (Ruiz Osuna 2007: 140). En muchos casos, dichas transformaciones no fueron más que el precedente de otras desarrolladas a mayor escala a partir del siglo III d.C. y que se enmarcan en el paso de la Colonia Patricia clásica a la Corduba tardoantigua.

\section{Agradecimientos}

La elaboración del presente artículo hubiese sido imposible sin la ayuda de un variado elenco de profesionales a quienes agradecemos sus distintas aportaciones, comentarios y ayuda proporcionada. Entre todos ellos quisiéramos dar las gracias a D. Pedro Soldado Barrios, párroco de la iglesia cordobesa de San José y Espíritu Santo, por las facilidades proporcionadas a la hora de fotografiar uno de los capiteles conservados en su interior. Este trabajo se inscribe en el marco del Proyecto de I+D+i DIDACTA: Digitalización e investigación de documentos y archivos científico-técnicos sobre Arqueología. La recuperación del legado material de D. Félix Hernández Giménez (1889-1975), concedido para el período 2016-2019 por la Secretaría de Estado de Investigación, Desarrollo e Innovación del Ministerio de Economía y Competitividad, dentro del Programa Estatal de Investigación, Desarrollo e Innovación Orientada a los Retos de la Sociedad, enmarcado a su vez en el Plan Estatal de Investigación Científica y Técnica y de Innovación 2013-2016 (Ref. HAR2015-66753-R).

\section{BIBLIOGRAFÍA}

Alarcón, L. y Montero, F. (2017): “The Traianeum and the urbanism of Italica". Civiltà romana. Rivista pluridisciplinare di studi su Roma antica e le sue interpretazioni 4: 251-270.

Arhens, S. (2005): Die Architekturdekoration von Italica. Iberia Archaeologica 6. Mainz, Verlag Philipp Von Zabern.

Becerra, D. (2019): Los materiales marmóreos del Traianevm de Italica. Tesis doctoral, Universidad de Sevilla. Inédita. Disponible (a partir de 2022) en: https://idus.us.es/handle/11441/84310.

Blázquez, J. M. (1993): Mosaicos romanos de España. Madrid, Cátedra.

Botella, D. (1995): "Intervención Arqueológica de Urgencia en la Plaza de Colón, 8". Anuario Arqueológico de Andalucía 1992, vol. III: 235-243.

Caballos, A.; Marín, J. y Rodríguez, M. (2006): Itálica arqueológica. Sevilla, Universidad de Sevilla.
Cánovas, A. (2010): "La arquitectura doméstica de la zona occidental de Colonia Patricia Corduba", en D. Vaquerizo y J.F. Murillo (eds.), El anfiteatro romano de Córdoba y su entorno urbano. Análisis arqueológico (ss. I-XIII d.C.). Monografías de Arqueología Cordobesa 19, vol. II: 415-438. Córdoba (2010), Córdoba, Universidad de Córdoba.

Felipe, A. M. (2013): “Decoración arquitectónica adrianea de Astigi, Écija (Sevilla)", en R. Hidalgo y P. León (eds.), Roma, Tibur, Baetica. Investigaciones adrianeas: 377-404. Sevilla, Universidad de Sevilla.

García Matamala, B. (2010): "Instalaciones industriales y comerciales en el suburbium occidentale", en D. Vaquerizo y J.F. Murillo (eds.), El anfiteatro romano de Córdoba y su entorno urbano. Análisis arqueológico (ss. I-XIII d.C.). Monografías de Arqueología Cordobesa 19, vol. II: 439-450. Córdoba (2010), Córdoba, Universidad de Córdoba.

Garriguet, J. A. (2002): El culto imperial en la Córdoba romana. Una aproximación arqueológica. Córdoba, Diputación de Córdoba.

Garriguet, J. A. (2013): "Novedades de escultura romana en Córdoba”, en F. Acuña, R. Casal y S. González (eds.), Escultura romana en Hispania VII. Homenaje al prof. Dr. Alberto Balil. Decoración arquitectónica adrianea de Astigi, Écija (Sevi1la)", Actas de la VII Reunión de Escultura Romana en Hispania: 377-402. Santiago de Compostela y Lugo (2011), La Coruña, Andavira.

Garriguet, J. A. (2018): "Un posible retrato de Adriano en el Palacio de Viana (Córdoba)", en C. Márquez y D. Ojeda (eds.), Escultura romana en Hispania VIII. Homenaje a Luis Baena del Alcázar. Actas de la VIII Reunión de Escultura Romana en Hispania: 579-595. Córdoba (2016), Córdoba, Universidad de Córdoba.

Gutiérrez Behemerid, M. A. (1983): "El capitel corintizante: su difusión en la Península Ibérica”. Boletín del Seminario de Estudios de Arte y Arqueología: 49: 73-104. http://uvadoc.uva.es/handle/10324/12776.

Gutiérrez Deza, M. I. (2016): Análisis de un centro de culto imperial de la Córdoba romana. El conjunto arquitectónico de la c/ Claudio Marcelo. Tesis doctoral, Universidad de Córdoba. Disponible en: https://helvia.uco.es/xmlui/handle/10396/13241 Fecha de consulta: 06/07/2019.

Gutiérrez Deza, M. I. y Felipe, A. M. (2009): "Una breve visión de la labor de los "marmorarii" de Villa Adriana”. Romula 8: 125-144.

Hidalgo, R. (1990): Informe de la Intervención Arqueológica de Urgencia en la ampliación de la Facultad de Filosofía y Letras de Córdoba, calle Almanzor 
$n^{o}$ 3. Informe administrativo (inédito) depositado en la Delegación Provincial de Cultura de la Junta de Andalucía en Córdoba. Expediente: 1341

Ibáñez, A. (1990): "Intervención Arqueológica de Urgencia en Ronda de los Tejares 6 de Córdoba". Anuario Arqueológico de Andalucía 1987, vol. III: 176-181.

Lázaro, L. (2013): Informe de la Actividad Arqueológica Preventiva de Control Arqueológico del proyecto de reforma y rehabilitación del Conservatorio Profesional de Danza "Luís del Río" y Escuela Superior de Arte Dramático "Miguel Salcedo Hierro" de Córdoba. Informe administrativo (inédito) depositado en la Delegación Provincial de Cultura de la Junta de Andalucía en Córdoba.

León Alonso, P. (1988): Traianeum de Italica. Sevilla, Monte de Piedad y Caja de Ahorros de Sevilla.

León Muñoz, A.; Murillo, J.F. y León, E. (2008): Informe-Memoria de la Intervención Arqueológica Puntual en el "Patio de Mujeres" del Alcázar de los Reyes Cristianos, de Córdoba. Informe administrativo (inédito) depositado en la Delegación Provincial de Cultura de la Junta de Andalucía en Córdoba.

León Pastor, E. (2010): "Portus Cordubensis", Anejos de Anales de Arqueología Cordobesa 2: 45-72.

López López, I. M. (1998a): Aproximación al conocimiento de la Córdoba romana: el ejemplo de la Casa Carbonell. Publicación en microficha número 163, Córdoba, Universidad de Córdoba.

López López, I. M. (1998b): Estatuas masculinas togadas y estatuas femeninas vestidas de colecciones cordobesas. Córdoba, Universidad de Córdoba.

López López, I. M. y Garriguet, J. A. (2000): "La decoración escultórica del foro colonial de Córdoba", en P. León y T. Nogales (eds.), Actas de la III Reunión sobre escultura romana en Hispania: 47-80. Córdoba (1997), Madrid, Ministerio de Educación, Cultura y Deporte.

López Rey, N. (2002): "Nuevos datos sobre la muralla este de Córdoba”. Arte, Arqueología e Historia 9: 103-109.

Mar, R.; Ruiz de Arbulo, J.; Vivó, D.; Beltrán, J. A. y Ferran, J. (2015): Tarraco. Arquitectura y urbanismo de una capital provincia romana, vol. II. La ciudad imperial. Documents d' Arqueología Clàssica 6. Tarragona, Universitat Rovira i Virgili.

Martín, I. (2012): Actividad Arqueológica Preventiva en la plaza Ramón y Cajal $n^{\circ} 2$ de Córdoba. Informe y Memoria. Informe administrativo (inédito) depositado en la Gerencia Municipal de Urbanismo del Ayuntamiento de Córdoba. Expediente: P543/2007.
Martins, M. y Fontes, L. (2010): “Bracara Augusta. Balanço de 30 anos de investigação arqueológica na capital da Galécia Romana”, en R. González, J. Ruiz de Arbulo (eds.). Simulacra Romae II. Rome, les capitales de province (capita prouinciarum) et la création d'un espace commun européen. Une approche archéologique: 111-124. Reims, Société Archéologique Champenoise.

Márquez, C. (1990): “Talleres romanos de capiteles corintizantes en Colonia Patricia Corduba durante el periodo adrianeo”. Archivo Español de Arqueología 63, no 161-162: 161-182.

Márquez, C. (1992): "Desarrollo de los órdenes arquitectónicos en los capiteles de Colonia Patricia Corduba", Madrider Mitteilungen 49: 113-132.

Márquez, C. (1993): Capiteles romanos de Corduba Colonia Patricia. Córdoba, Monte de Piedad y Caja de Ahorros de Córdoba.

Márquez, C. (1998): La decoración arquitectónica de Colonia Patricia. Una aproximación a la arquitectura y urbanismo de la Córdoba romana. Córdoba, Universidad de Córdoba y Caja de Ahorros y Monte de Piedad de Córdoba.

Márquez, C. (2002): "Relieves de Niké y representaciones de provinciae”, en A. Ventura, C. Márquez, A. Monterroso y M.A. Carmona (eds.), El teatro romano de Córdoba. Catálogo de la exposición: $255-$ 260. Córdoba, Universidad de Córdoba.

Márquez, C. (2013): “Caracteres generales de la ornamentación arquitectónica en la Villa de Adriano de Tívoli", en R. Hidalgo y P. León (eds.), Roma, Tibur, Baetica. Investigaciones adrianeas: 179-198. Sevilla, Universidad de Sevilla.

Márquez, C. (2015): "Talleres atenienses en la Villa Adriana de Tívoli”, en S. López, J. M. Maestre y A. Urbán (coords.), Studia Angelo Urbano dicata: 493502. Madrid, Instituto de Estudios Humanísticos.

Melchor, E. (1993): "La construcción pública en Hispania Romana: iniciativa imperial, municipal y privada". Memorias de Historia Antigua 13-14: 129-170.

Molina, A. (2017): “Actividad Arqueológica Preventiva en la Avda. América, $n^{\circ} 5$ (antiguo Hotel Gran Capitán), de Córdoba". Anuario Arqueológico de Andalucía 2008: 1624-1635.

Molina, A. y Sánchez, M. I. (2003): “Una aportación a las necrópolis tardorromanas de Corduba: el sector funerario de la calle Lucano n 7 y 9 de Córdoba". Anales de Arqueología Cordobesa 13-14: 355-389.

Montejo, A. J. (1998): Informe Sucinto de los resultados obtenidos durante la Intervención Arqueológica de Urgencia en Magistral González Francés $n^{\circ} 23$. 
Córdoba. Informe administrativo (inédito) depositado en la Delegación Provincial de Cultura de la Junta de Andalucía en Córdoba. Expediente: 1562.

Moreno Almenara, M. (e.p.): “Actividad Arqueológica Puntual realizada en apoyo a la puesta en valor de la domus de la llamada Casa Castejón (antiguo Palacio del Bailío) de Córdoba". Anuario Arqueológico de Andalucía.

Moreno González, M. F. (1996): Aproximación al estudio de la decoración musivaria en Colonia Patricia Corduba, Publicación en microficha número 134, Córdoba, Universidad de Córdoba

Murillo, J. F. (2010): “Colonia Patricia Corduba hasta la dinastía flavia. Imagen urbana", en R. González, J. Ruiz de Arbulo (eds.), Simulacra Romae II. Rome, les capitales de province (capita prouinciarum) et la création d'un espace commun européen. Une approche archéologique: 71-93. Reims, Société Archéologique Champenoise.

Murillo, J. F.; Carrillo, J. R.; Moreno, M.; Ruiz, D. y Vargas, S. (2002): "Los monumentos funerarios de Puerta de Gallegos", en D. Vaquerizo (ed.), Colonia Patricia Corduba. Espacios y usos funerarios en el Occidente Romano: 247-274. Córdoba, Universidad de Córdoba.

Ortiz, L. (2011): "Una villa romana en Ronda de Marrubial. Del s. I al IV d.C.” Romula 10: 253-276.

Peña, A. (2003): "Materiales de un posible edificio de época adrianea reutilizados en la Mezquita Aljama de Córdoba". Romula 2: 197-214.

Peña, A. (2010): Estudio de la decoración arquitectónica romana y análisis del reaprovechamiento de material en la Mezquita Aljama de Córdoba. Córdoba, Universidad de Córdoba.

Pérez Olmedo, E. (1996): Revestimientos de Opus Sectile en la península ibérica. Studia Archaeologica 84. Valladolid, Universidad de Valladolid.

Pizarro, G. (2014): El abastecimiento de agua a Córdoba. Arqueología e Historia. Córdoba, Universidad de Córdoba.

Portillo, A. (2015): “Una posible restauración del templo de la calle Morería en el forum novum de Colonia Patricia en el siglo II". Anales de Arqueología Cordobesa 25-26: 71-82. https://doi.org/10.21071/ aac.v0i25-26.6415

Portillo, A. (2016): El templo de la calle Morería en el Forum Novum de Colonia Patricia. Análisis arquitectónico y funcional. Tesis doctoral, Universidad de Córdoba. Disponible en: https://helvia.uco. es/xmlui/handle/10396/13226 Fecha de consulta: 12/06/2019.
Portillo, A. (2018): El forum novum de Colonia Patricia. Análisis arquitectónico, estilístico y funcional. Anejos de Archivo Español de Arqueología 83. Mérida, Instituto de Arqueología de Mérida.

Portillo, A. y Ruiz-Bueno, M.D. (2017): “Un nuevo complejo religioso de época imperial en Colonia Patricia. El recinto de culto de c. Tejón y Marín 14 (Córdoba)". Lucentum 36: 239-260. https://doi. org/10.14198/LVCENTVM2017.36.14

Rodero, S. (2002): "Algunos aspectos de la decoración arquitectónica del Traianeum de Itálica". Romula 2: 75-106.

Rodero, S. (2004): "Evolución de la topografía urbana al Este de la Puerta Piscatoria: I.A.U. en la Posada de la Herradura". Anales de Arqueología Cordobesa 15: 173-206. http://hdl.handle.net/10396/3596.

Rodríguez Neila, J. F. (1988): Historia de Córdoba. Del Amanecer prehistórico al ocaso visigodo. Córdoba, Monte de Piedad y Caja de Ahorros de Córdoba.

Romero, D. (2016): La ciudad hispanorromana en el s. II d.C. Consolidación y transformación de un modelo urbano. Tesis doctoral, Universidad de Córdoba. Disponible en: https://helvia.uco.es/ xmlui/handle/10396/14222 Fecha de consulta: 15/07/2019.

Ruiz Bueno, M. D. (2016): Topografía, imagen y evolución urbanística de la Córdoba clásica a la tardoantigua (ss. II-VII d.C.). Tesis doctoral, Universidad de Córdoba. Disponible en: http://hdl.handle. net/10396/14142 Fecha de consulta: 24/06/2019.

Ruiz Bueno, M. D. (2018): Dinámicas topográficas urbanas en Hispania. El espacio intramuros entre los siglos II y VII d.C. Munera 44. Bari, Edipuglia. http://dx.doi.org/10.4475/855

Ruiz Bueno, M. D. y Vaquerizo, D. (2016): "Las murallas como paradigma urbano. Investigación y diacronía en Corduba (ss. II-VII d.C.)”. Cuadernos de Arqueología de la Universidad de Navarra 24: 163 192. https://doi.org/10.15581/012.24.001

Ruiz Osuna, A. B. (2007): La monumentalización de los espacios funerarios en Colonia Patricia Corduba (ss. I a.C. - II d.C.). Monografías de Arqueología Cordobesa 16. Córdoba, Universidad de Córdoba.

Ruiz Osuna, A. B. (2010): Colonia Patricia, centro difusor de modelos: topografia y monumentalización funerarias en Baetica. Monografías de Arqueología Cordobesa 18. Córdoba, Universidad de Córdoba.

Ruiz Osuna, A. B. y Ruiz, M. D. (2018): "Novedades de musivaria cordobesa: puesta al día de su estudio y su uso como recurso patrimonial", en J.M. Álvarez y $\mathrm{M}^{\mathrm{a}}$.L. Neira (eds.), Estudios sobre mosaicos 
romanos. Dimas Fernández-Galiano. In Memoriam: 329-372. Madrid, Esfera de los Libros.

Sánchez Madrid, S. y Vaquerizo, D. (2010): “Epigrafía gladiatoria cordubense", en D. Vaquerizo y J.F. Murillo (eds.), El anfiteatro romano de Córdoba y su entorno urbano. Análisis arqueológico (SS. I-XIII d.C.). Monografías de Arqueología Cordobesa 19, vol. II: 480-500. Córdoba (2010), Córdoba, Universidad de Córdoba.

Vaquerizo, D. (2001): "Formas arquitectónicas funerarias de carácter monumental en Colonia Patricia”. Archivo Español de Arqueología 74: 131-160. https://doi.org/10.3989/aespa.2001.v74.151

Vaquerizo, D. (2014): “Ciudad y territorio en el Valle Medio del Betis: apuntes al hilo de una realidad dual, pero esquiva", en D. Vaquerizo, J.A. Garriguet y A. León (eds.), Ciudad y territorio: transformaciones materiales e ideológicas entre la época clásica y el Altomedievo. Monografías de Arqueología Cordobesa 20: 11-40. Córdoba, Universidad de Córdoba.

Vaquerizo, D. y Ruiz, M. D. (2014): "Últimas investigaciones arqueológicas en Corduba, Colonia Patricia: una propuesta de síntesis", en M. Martín y J.C. Sáenz (eds.), Modelos edilicios y prototipos en la monumentalización de las ciudades de Hispania: 15-31. Zaragoza, Universidad de Zaragoza.
Vargas, S. (2010): "El vicus del suburbium occidental de Colonia Patricia visto a través de sus conjuntos cerámicos", en D. Vaquerizo y J.F. Murillo (eds.), El anfiteatro romano de Córdoba y su entorno urbano. Análisis arqueológico (ss. I-XIII d.C.). Monografías de Arqueología Cordobesa 19, vol. II: 450-466. Córdoba, Universidad de Córdoba.

Vargas, S.; Pizarro, G. y Salinas, E. (2010): “Actividad Arqueológica Preventiva en Garaje Alcázar; c/ Cairuán $n^{\circ}$ 1, Córdoba". Anuario Arqueológico de Andalucía 2004, vol. II: 379-395.

Ventura, A. (1996): El abastecimiento de agua a la Córdoba romana II. Acueductos, ciclo de distribución y urbanismo. Córdoba, Universidad de Córdoba.

Ventura, A. (2009): "Las élites de Colonia Patricia, año 5 a.C.: un ejemplo de puesta en escena literaria y monumental", en M. P. García-Bellido (ed.), Espacios, usos y formas de la epigrafia hispana en épocas antigua y tardoantigua. Homenaje al doctor Armin U. Stylow. Anejos de Archivo Español de Arqueología 48: $375-$ 395. Mérida, Instituto de Arqueología de Mérida.

Ventura, A. y Márquez, C. (2005): “Orbis terrarum gentiumque: un programa decorativo antoniniano en el teatro romano de Córdoba", en J. M. Noguera y E. Conde (eds.), Preactas de la V Reunión sobre escultura romana en Hispania: 109-113. Murcia (2005). Murcia, Dirección General de Cultura. 
